\title{
Tolvaptan: the evidence for its therapeutic value in acute heart failure syndrome
}

\author{
Arash Aghel, W. H. Wilson Tang
}

Section of Heart Failure and Cardiac Transplantation Medicine, Department of Cardiovascular Medicine, Cleveland Clinic, Cleveland, Ohio, USA

\begin{abstract}
Introduction: Acute heart failure syndrome (AHFS) is one of the leading causes of hospital admission in the US. Tolvaptan is a vasopressin $\mathrm{V}_{2}$ receptor antagonist that blocks the effect of arginine vasopressin (AVP) in reabsorbing water from the collecting ducts of the nephrons in congestive heart failure.
\end{abstract}

Aims: To review the evidence for utilizing tolvaptan in the treatment of AHFS.

Evidence review: Several clinical trials have sought to assess the clinical effects of tolvaptan in heart failure. Compared with placebo, tolvaptan has been shown to reduce bodyweight and improve serum sodium in patients with AHFS without worsening renal function. Tolvaptan appeared to be well tolerated with a good safety profile. It caused a significant reduction in pulmonary capillary wedge pressure compared with placebo, but has yet to demonstrate reversal of cardiac remodeling. A large-scale mortality trial showed no differences in long-term mortality rates between tolvaptan and placebo, although early symptom relief was apparent with tolvaptan and lower diuretic use.

Place in therapy: Tolvaptan has shown to be safe and effective in treating congestion in AHFS. Free water excretion in fluid-overloaded patients vulnerable to cardiorenal compromise with standard diuretic therapy makes $\mathrm{V}_{2}$ vasopressin receptor blockade an attractive adjunct to standard medical therapy aimed at reducing congestion in AHFS.

Core Evidence. 2008;3(1):31-43

doi: $10.3355 /$ ce. 2008.010

Key words: acute decompensated heart failure, vasopressin, tolvaptan, aquaretic, diuretics, evidence

Core evidence place in therapy summary for tolvaptan as an addition to standard therapy in patients with acute heart failure syndrome

\begin{tabular}{|c|c|c|}
\hline Outcome measure & Evidence & Implications \\
\hline \multicolumn{3}{|l|}{ Patient-oriented evidence } \\
\hline Decrease in fluid balance and bodyweight & Clear & $\begin{array}{l}\text { Consistent reduction in bodyweight and favorable } \\
\text { fluid balance without detrimental electrolyte } \\
\text { imbalance }\end{array}$ \\
\hline Decrease in symptom burden & Clear & $\begin{array}{l}\text { Tolvaptan improves symptoms in patients with acute } \\
\text { heart failure syndrome }\end{array}$ \\
\hline Safety and tolerability & Clear & Tolvaptan has an acceptable tolerability profile \\
\hline Improvement in quality of life & Substantial & $\begin{array}{l}\text { Improved symptoms balances troublesome } \\
\text { side effects }\end{array}$ \\
\hline Neutral effects in morbidity and mortality & Substantial & $\begin{array}{l}\text { Tolvaptan has not been associated with decreased } \\
\text { mortality compared with placebo }\end{array}$ \\
\hline \multicolumn{3}{|l|}{ Disease-oriented evidence } \\
\hline Improvement in serum sodium & Clear & $\begin{array}{l}\text { Tolvaptan improves serum sodium concentrations. } \\
\text { Hyponatremia is a marker of poor outcome in } \\
\text { heart failure }\end{array}$ \\
\hline Increased urine output & Clear & Relieves congestion \\
\hline Preservation of renal function & Clear & $\begin{array}{l}\text { Tolvaptan does not worsen renal function; worsening } \\
\text { renal function is a known predictor of mortality in } \\
\text { heart failure }\end{array}$ \\
\hline Neutral effect on ventricular volumes & Substantial & $\begin{array}{l}\text { Drugs with mortality benefit in heart failure have } \\
\text { generally shown to halt the process of remodeling }\end{array}$ \\
\hline Improvement in hemodynamic measures & Substantial & $\begin{array}{l}\text { Tolvaptan reduces pulmonary capillary wedge } \\
\text { pressure and congestion }\end{array}$ \\
\hline \multicolumn{3}{|l|}{ Economic evidence } \\
\hline Cost effectiveness & No evidence & \\
\hline
\end{tabular}


Tolvaptan | place in therapy review

\section{Scope, aims, and objectives}

Arginine vasopressin (AVP) has long been known to play a central role in the pathophysiology of congestive heart failure. Tolvaptan is an oral, nonpeptide vasopressin $V_{2}$ receptor antagonist that blocks the effects of AVP on renal collecting tubules, resulting in aquaresis and resolution of hyponatremia. The objective of this article is to review the available evidence for the use of tolvaptan in acute heart failure syndrome (AHFS), and includes results from several clinical studies. We also provide an overview of AHFS, its economic impact, and current treatment options to put into perspective what tolvaptan may provide.

\section{Methods}

A literature search was conducted on October 4, 2007 in several databases using the search strategy stated below:

- Ovid Medline ${ }^{\circledR}$ (http://gateway.uk.ovid.com/gw2/ovidweb.cgi): 1950 to September 4, 2007. Search strategy (1) "tolvaptan"; (2) "tolvaptan" with CAS registry \#; (3) "heart failure, congestive/ or edema, cardiac/" as mesh head; and (4) "((Heart or cardiac or myocard :) adj15 fail :)". Search results were then crossed by searching for ( 1 or 2 ) and ( 3 or 4$)$. The results were limited to English language resources

- EMBASE (http://gateway.tx.ovid.com/gw1/ovidweb.cgi): 1980 to 2007 week 39 and EMBASE drugs and pharmacology 1980 to 4th Quarter 2007. Search strategy (tolvaptan and CHF) OR tolvaptan and ((heart or cardiac or myocard :) adj15 fail :) limiting results to English language resources

- All evidence based medicine reviews, including Cochrane DSR, ACP Journal Club, DARE, and CCTR. Search strategy "tolvaptan"

- BIOSIS search (http://etextb.ohiolink.edu/bin/gat.exe). Search strategy (tolvaptan AND chf) AND (english.la.) OR ((tolvaptan AND fail\$) AND (myocard\$ OR cardiac OR heart)) AND (english. la.). The results were crossed with (tolvaptan AND "14506") AND (english.la.)

- National Guidelines (www.guidelines.gov). Search strategy "tolvaptan"

- Clinical Trial Registry (www.clinicaltrials.gov). Search strategy "tolvaptan"

- NHS HTA (www.ncchta.org). Search strategy "tolvaptan"

- Web of Science: 1980+ (Science Citation Index, Social Sciences Citation Index \& Arts \& Humanities Citation Index). Search strategy: "tolvaptan AND (CHF OR ( myocard* SAME fail*) OR (heart SAME fail*) OR (Cardiac SAME fail ${ }^{\star}$ )

- SCOPUS (www.scopus.com). Search strategy "tolvaptan"

- Cardiosource Plus (www.cardiosourceplus.com). Search strategy "tolvaptan"

After removal of duplicates a total of 97 citations were identified from the above search engines, journals, and websites. Records were reviewed manually and 89 citations were excluded because of tolvaptan use beyond the setting of heart failure, animal studies, or nonsystematic reviews. The remaining records were then classified into five classes of evidence based on the design of the study, with Level 1 evidence representing the strongest level of evidence and Level 5 representing the weakest evidence as summarized in Table 1.

\section{Table 1 | Evidence base included in the review}

Number of records

\begin{tabular}{lcc|}
\cline { 2 - 3 } Category & Full papers & Abstracts \\
\hline Initial search & 97 & 7 \\
records excluded & 89 & 5 \\
records included & 8 & 2 \\
Additional studies identified & 0 & 0 \\
Level 1 clinical evidence & 0 & 0 \\
Level 2 clinical evidence (RCT) & 6 & 1 \\
Level $\geq 3$ clinical evidence & & 1 \\
$\quad$ trials other than RCT & 2 & 0 \\
$\quad$ case reports & 0 & 0 \\
Economic evidence & 0 & \\
\hline $\begin{array}{l}\text { For definition of levels of evidence see Editorial Information on inside back cover of journal } \\
\text { or website http://www.coremedicalpublishing.com. }\end{array}$ & & \\
RCT, randomized controlled trial. &
\end{tabular}

\section{Disease overview}

The prevalence of heart failure in the US is estimated at more than 5 million, with an incidence approaching 10 per 1000 in persons older than 65 years of age (Rosamond et al. 2007). Over the past 30 years, the rate of hospitalizations for AHFS has increased from 399000 in 1979 to 1099000 in 2004: an astounding increase of $175 \%$ (Rosamond et al. 2007). Data from ambulatory care departments, hospital outpatient clinics, and emergency room admissions between 1999 and 2000 documented more than 3400000 encounters due to AHFS. Naturally, this all translates into costly care. In the US, the overall cost of heart failure in 2007 was $\$$ US33.2 billion (Rosamond et al. 2007). Similarly, data from European countries show that more than half of the cost of managing heart failure is related to inhospital expenses (Berry et al. 2001).

Over the past few decades, better understanding of the underlying pathophysiology has led to significant change in the treatment of chronic heart failure, and the targeting of neurohormonal abnormalities that drive disease progression. Drugs inhibiting the renin-angiotensin-aldosterone (RAAS) and sympathetic nervous systems have become the standard of care following several landmark clinical trials demonstrating their effectiveness. However, few drugs have been developed in the setting of AHFS, which is arbitrarily defined as an acute onset of worsening signs and symptoms of heart failure requiring medical attention (Gheorghiade \& Mebazaa 2005). This decompensated state has long been recognized as the "congestion" presentation of heart failure. 
We have learned a tremendous amount regarding the contemporary management of AHFS from the large 187565 patient Acute Decompensated Heart Failure National Registry (ADHERE) (Adams et al. 2005), and the Euroheart Failure Survey II (Nieminen et al. 2006). The diagnosis of AHFS is a combination of clinical presentations (especially with worsening signs and symptoms of congestion), often in conjunction with verification by diagnostic testing in the majority of cases. Patients suspected as having AHFS often carry a preexisting cardiac condition, and evaluation of cardiac function is appropriate to categorize the heart failure type (systolic or diastolic heart failure) and to characterize the severity of the disease. However, it is important to point out that this categorization is largely historic: the majority of evidence-based treatment strategies have focused on patients with left ventricular systolic dysfunction. Recent adoption of natriuretic peptide testing as an aid to the diagnosis of heart failure in the acute setting has been proven to enhance diagnostic accuracy and appropriateness in clinical management and improve clinical outcomes (Maisel 2003; Mueller et al. 2004; Moe et al. 2007). Guidelines also emphasize that interpretation of the natriuretic peptide values should be in the context of all available clinical data bearing on the diagnosis of heart failure.

Hospital admissions have been recommended in patients where more intensive diagnosis and management are warranted: those with hypotension, worsening renal function, altered mental status, severe dyspnea with respiratory compromise, hemodynamic compromise from congestion or underlying cardiac diseases (ischemia, arrhythmia), or severe electrolyte disturbances. Hospitalization should also be considered in new onset heart failure with significant congestion.

Table 2 outlines the appropriate treatment goals for AHFS.

Table 2 | Treatment goals for patients admitted with AHFS (HFSA 2006, with permission)

Improve symptoms, especially congestion and low output syndromes

Optimize volume status

Identify etiologies and precipitating factors

Optimize chronic oral therapy

Minimize side effects

Identify patients who might benefit from revascularization

Educate patients concerning medications and self assessment of heart failure

Consider and, where possible, initiate a disease management program

AHFS, acute heart failure syndrome.

\section{Pathophysiology}

The underlying pathophysiology of AHFS is complex and poorly understood (Figure 1), which may explain why the search for effective drug therapy is challenging. It is, however, becoming more and more clear from intracardiac monitoring device data and narrative analyses that the acuity of AHFS can extend beyond 2-3 weeks prior to the date of hospital admission (Schiff et al. 2003; Yu et al. 2005). Several well-recognized and potentially preventable precipitating factors have been identified over the years. These include medication and dietary nonadherence, use of harmful medications, infections, anemia, arrhythmias, uncontrolled hypertension, myocardial infarction, or emotional/ stressful events (Opasich et al. 2001; Fomiga et al. 2007). These observations may explain why in some cases AHFS develops due to a logistic problem (insufficient self care), while in other cases AHFS develops due to underlying biologic processes.

Renal involvement remains an important factor that drives the development of AHFS. The pivotal role of the kidney to remove salt and water has long been recognized. Previously, it has been postulated that in the setting of diminished cardiac output leading to vascular underfilling, activation of neurohormonal systems, including the RAAS and the autonomic nervous system, are operative, and contribute to the kidneys' ability to overdrive sodium retention leading to both salt and water retention and congestion (Packer 1992). Support for this hypothesis includes the propensity to develop AHFS in patients with marginal renal reserve as well as in patients with more advanced heart failure as a result of more diminished left ventricular ejection fraction (LVEF) or low cardiac output. This is also the primary basis for the effectiveness of loop diuretic therapy in volume-overloaded states, where enhancing the urinary removal of sodium (natriuresis) can lead to effective relief of congestion.

Recent observations have provided evidence that diastolic rather than systolic dysfunction is the driving factor in the progression of AHFS (Gandhi et al. 2001). This is consistent with observations that the majority of patients presenting with AHFS in ADHERE had preserved blood pressure, with almost $50 \%$ experiencing relative hypertension (systolic blood pressure beyond $140 \mathrm{mmHg}$ ) (Adams et al. 2005).

\section{Current treatment options}

While several professional societies have published extensive guidelines for the management of chronic heart failure, there are only two major guidelines available for AHFS: the European Society of Cardiology (ESC) guidelines (Nieminen et al. 2005) and the Heart Failure Society of America guidelines (HFSA 2006). However, both guidelines have comparatively limited evidence available to direct thorough support for current treatment strategies, in part because many treatment strategies preceeded the era of large-scale randomized controlled trials to justify their broad adoption.

The primary aims of therapy have not evolved beyond (1) the reduction of congestive state with salt and water removal; and (2) correction of underlying hemodynamic derangements by either unloading the failing ventricle or by overdriving inotropy. A more contemporary secondary aim of AHFS therapy relates to the preservation of renal function. Table 3 provides an evidencebased summary of currently approved AHFS therapy.

\section{Relieving congestion}

At present, diuretics are the mainstay of therapy in acute heart failure to reduce volume overload that results in congestion. This strategy is almost reflexive in the acute care setting once the diagnosis of AHFS is established. However, the ADHERE registry has suggested that there may be adverse effects from treatment 


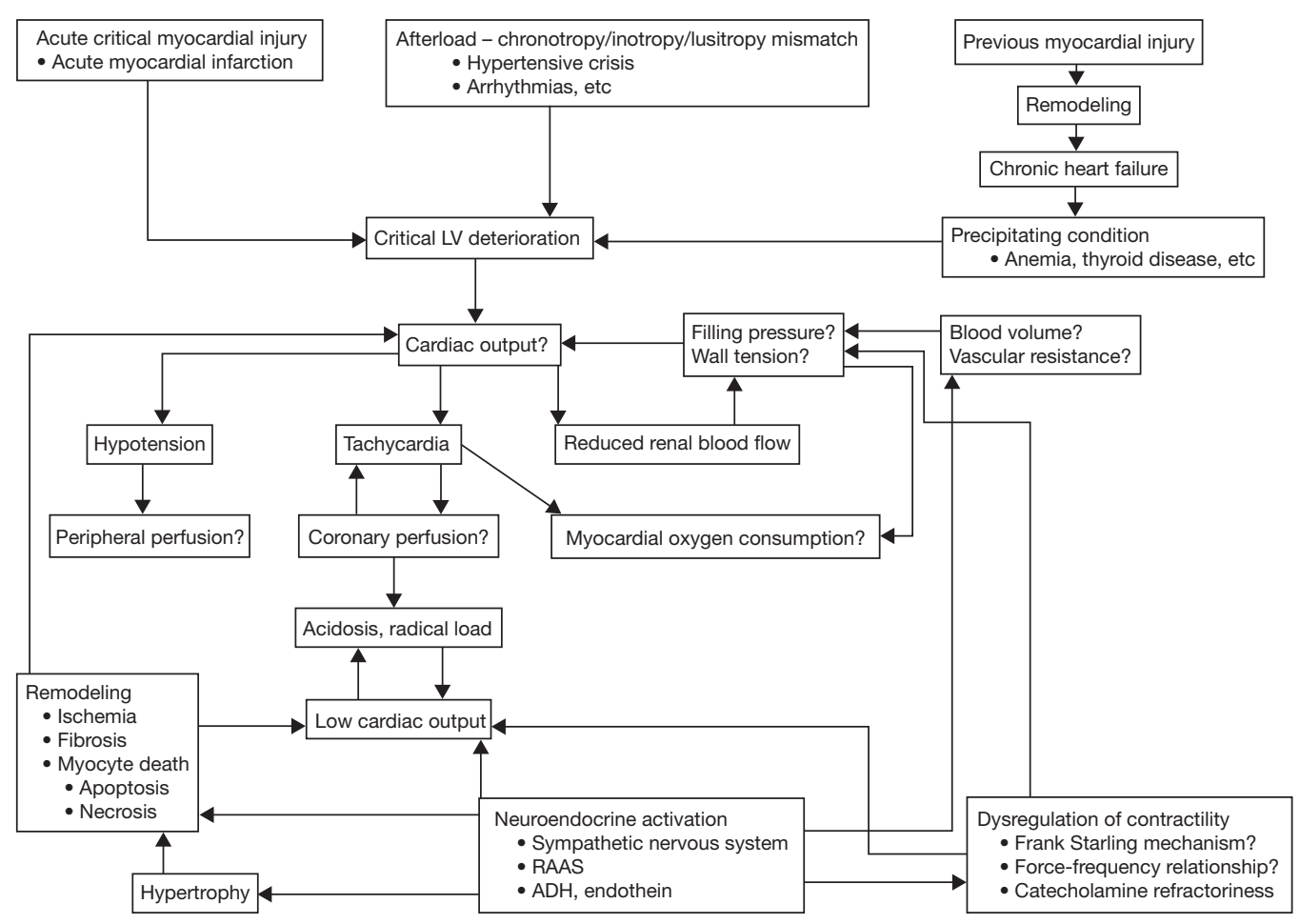

Fig. 1 | Pathophysiology of heart failure (with permission from Nieminen et al. Eur Heart J. 2005;26:384-416. Oxford University Press). $\mathrm{ADH}$, antidiuretic hormone; LV, left ventricle; RAAS, renin angiotensin aldosterone system.

with intravenous loop diuretics in patients who present with AHFS (Fonarow et al. 2005). It is also important to point out that few contemporary prospective clinical trials have been conducted to better understand the best strategy of use for these agents, appropriate doses, and routes of administration, as well as the most appropriate goals of therapy.

Recently, there has been resurgence in the concept of mechanical removal of salt and water by means of ultrafiltration. Newer and simpler devices have generated potential to utilize the ultrafiltration strategy beyond traditional dialysis settings, while maintaining the amount of salt and solute removal. The Ultrafiltration versus Intravenous Diuretics for Patients Hospitalized for Acute Decompensated Heart Failure (UNLOAD) study showed that venovenous ultrafiltration produced more weight loss at 48 hours, but no greater improvement in dyspnea or changes in natriuretic peptide levels when compared with loop diuretics in patients with AHFS (Costanzo et al. 2007). The effects of this approach in terms of safety and efficacy remain to be determined, although in UNLOAD the ultrafiltration arm was associated with fewer adverse clinical events at long-term followup (Costanzo et al. 2007).

\section{Unloading the ventricle}

Vasodilators are another class of drugs used for the treatment of AHFS, which include nitroglycerin, nitroprusside, and natriuretic peptides. Although useful in the acute setting to counteract compensatory arterial vasoconstriction, hypotension and renal insufficiency are potential adverse effects. Of the above mentioned drugs, nitroglycerin is a more balanced vasodilator, but its use has been limited by the development of tachyphylaxis, nitrate tolerance, and headaches. In the EuroHeart Failure Survey, 32\% of patients with AHFS in Europe received intravenous nitroglycerin during their hospitalization, compared with only $10 \%$ in the ADHERE study in the US (Komajda et al. 2003). Nitroprusside is a potent vasodilatory agent with a favorable hemodynamic profile of predominantly afterload reduction, but requires invasive hemodynamic monitoring in the intensive care setting. Side effects include thiocyanate poisoning, which is relatively uncommon. Nesiritide is a recombinant form of endogenous B-type natriuretic peptide with vasodilator properties. In the Vasodilation in the Management of Acute Congestive Heart Failure (VMAC) study, nesiritide showed a significant acute (3 hour) improvement in dyspnea versus placebo, but not when compared with nitroglycerin (Abraham et al. 2005). However, the use of nesiritide has been dogged by conflicting evidence regarding its long-term safety profile and potential to worsen renal function (SacknerBernstein et al. 2005). The effect of intravenous angiotensinconverting enzyme (ACE) inhibitors on clinical outcomes has not been studied in AHFS populations and the use of these agents is not recommended based on concerns of acute administration in the setting of post-infarction heart failure.

Other vasodilators have been studied in the setting of AHFS but have yet to receive approval for use in the US. Levosimendan, 


\section{Table 3 | Current evidence-based therapies for acute heart failure syndrome (AHFS)}

\begin{tabular}{|c|c|c|c|}
\hline Drug or class & Evidence & Indication & Main adverse effects \\
\hline Loop diuretics & $\begin{array}{l}\text { Never evaluated in large-scale randomized } \\
\text { clinical trials }\end{array}$ & AHFS to relieve congestion & $\begin{array}{l}\text { Hypotension, electrolyte abnormalities, } \\
\text { and worsening renal function }\end{array}$ \\
\hline \multicolumn{4}{|l|}{ Vasodilators } \\
\hline nesiritide & $\begin{array}{l}\text { Improves hemodynamics and reduces } \\
\text { dyspnea, neutral survival benefit (Abraham } \\
\text { et al. 2005) }\end{array}$ & AHFS to improve symptoms & $\begin{array}{l}\text { Hypotension, potential of worsening } \\
\text { renal function }\end{array}$ \\
\hline nitrates & $\begin{array}{l}\text { High-dose isosorbide dinitrate more effective } \\
\text { than furosemide in controlling severe } \\
\text { pulmonary edema (Cotter et al. 1998) }\end{array}$ & $\begin{array}{l}\text { First-line therapy for AHFS with } \\
\text { adequate blood pressure }\end{array}$ & $\begin{array}{l}\text { Hypotension, headaches, } \\
\text { development of nitrate tolerance }\end{array}$ \\
\hline sodium nitroprusside & $\begin{array}{l}\text { Favorable hemodynamic effects (Guiha et } \\
\text { al. 1974), no data on survival benefit, may } \\
\text { increase risk in post-Ml patients (Cohn et al. } \\
\text { 1982) }\end{array}$ & Severe AHFS, hypertensive crisis & $\begin{array}{l}\text { Hypotension, cyanide toxicity, } \\
\text { accumulation in renal insufficiency }\end{array}$ \\
\hline \multicolumn{4}{|l|}{ Inotropes } \\
\hline dopamine/dobutamine & $\begin{array}{l}\text { Shown to improve symptoms in small scale } \\
\text { studies (Liang et al. 1984) }\end{array}$ & $\begin{array}{l}\text { AHFS with hypotension and peripheral } \\
\text { hypoperfusion }\end{array}$ & $\begin{array}{l}\text { Tachyarrhythmias, may increase } \\
\text { mortality }\end{array}$ \\
\hline milrinone & $\begin{array}{l}\text { No effect on duration of hospital stay or } \\
\text { mortality (Cuffe et al. 2002) }\end{array}$ & $\begin{array}{l}\text { AHFS refractory to diuretics and } \\
\text { vasodilators with preserved blood } \\
\text { pressure }\end{array}$ & $\begin{array}{l}\text { Sustained hypotension and } \\
\text { tachyarrhythmia }\end{array}$ \\
\hline levosimendan & $\begin{array}{l}\text { No mortality benefit, reduces symptoms } \\
\text { (Cleland et al. 2007; Mebazaa et al. 2007) }\end{array}$ & AHFS & $\begin{array}{l}\text { Increased rate of atrial fibrillation and } \\
\text { ventricular tachycardia }\end{array}$ \\
\hline Ultrafiltration & $\begin{array}{l}\text { More weight reduction than loop diuretics } \\
\text { (Costanzo et al. 2007) }\end{array}$ & $\begin{array}{l}\text { AHFS resistant to diuretics, or } \\
\text { cardiorenal syndrome }\end{array}$ & $\begin{array}{l}\text { Invasive, loss of solutes, procedural } \\
\text { complications }\end{array}$ \\
\hline
\end{tabular}

a calcium sensitizer, is in clinical use in several countries in Europe, South America, and Asia. In the Randomized Multicenter Evaluation of Intravenous Levosimendan Efficacy versus Placebo in the Short-Term Treatment of Decompensated Heart Failure (REVIVE)-2 data, levosimendan resulted in a favorable effect on the primary endpoint (a clinical composite of clinical status assessment and major clinical events at 6 hours, 24 hours, and 5 days), but was associated with a higher incidence of adverse events, such as hypotension and arrhythmias (Cleland et al. 2006). The Survival of Patients With Acute Heart Failure in Need of Intravenous Inotropic Support (SURVIVE) study showed that short-term use of levosimendan and dobutamine was associated with similar postdischarge mortality at 180 days (Mebazaa et al. 2007). Tezosentan, an intravenous endothelin receptor antagonist, has also been studied as a potent vasodilator in AHFS. However in the Value of Endothelin Receptor Inhibition with Tezosentan in Acute Heart Failure Studies (VERITAS), tezosentan failed to improve symptoms or long-term clinical outcomes (McMurray et al. 2007).

\section{Overdrive inotropy}

Usage of inotropic therapy has been popularized by early pathophysiologic concepts of inadequacy of the failing heart to provide "forward" flow. However, several studies in both acute and chronic heart failure settings have highlighted the potential long-term mortality risk of inotropic therapy. Currently, inotropic therapy such as dobutamine (catecholamines) or milrinone (phosphodiesterase-3 inhibitors) are restricted to end-stage, low cardiac output heart failure patients refractory to standard medical therapy, as routine administration in AHFS has been associated with poor outcomes in various clinical trials (Cuffe et al. 2002). Although dobutamine, dopamine, and milrinone improve hemodynamics, this improvement is often associated with significant adverse effects that include hypotension, atrial and ventricular arrhythmias, and possibly increased postdischarge mortality.

\section{Unmet needs}

Despite the large number of patients admitted every year for AHFS and the promise of several drug therapies with the launch of large-scale clinical trial investigations, the current treatment strategy has yet to differ substantially from that of a few decades ago. Intravenous loop diuretics remain the mainstay of therapy mainly due to their effectiveness in relieving symptoms of AHFS and their low cost. However, there has been increasing recognition of the potential hazards of cardiorenal compromise that overzealous use of acute or chronic loop diuretic therapy may cause (Neuberg et al. 2002). Another often accepted but poorly defined risk is the contribution of electrolyte disturbance during acute administration of aggressive loop diuretic therapy with AHFS admissions. Diuretic therapy has well-recognized side effects including electrolyte abnormalities, renal impairment, and neurohormonal activation (Bayliss et al. 1987).

What is more alarming is that our current strategy is not as effective when symptom relief is the only measure of treatment success. Results from the ADHERE registry show that at least $20 \%$ of patients with acute decompensated heart failure have no 
Tolvaptan | place in therapy review

change or an increase in bodyweight during their hospitalization, and $30 \%$ have some improvement but are still symptomatic at discharge (Adams et al. 2005). These observations highlight the need for effective drug therapy to improve management in this patient population.

Clinical trials of AHFS therapy now look beyond symptomatic relief, but even reliable surrogate markers such as bodyweight reduction and lowering natriuretic peptide levels have yet to be widely accepted due to their inconsistent relationship with longterm clinical outcomes.

\section{Clinical evidence with tolvaptan}

AVP is a neurohypophysial peptide hormone synthesized in the supraoptic and paraventricular nuclei in the hypothalamus and released by the posterior pituitary primarily for the maintenance of plasma osmolality through renal free water regulation (Lee et al. 2003). AVP exerts its effects by three distinct receptors: the $V_{1 A}$ receptor subtype is present on vascular smooth muscle cells where it mediates vascular constriction; $V_{2}$ receptors are present predominantly in the kidney collecting tubules where they mediate free water reabsorption; $V_{1 B}$, or $V_{3}$, receptors are found in the anterior pituitary and they mediate adrenocorticotropin release (Verbalis 2002). As expected, the role of fluid regulation primarily resides on the $\mathrm{V}_{2}$ receptor effects. Induction of intracellular cyclic AMP triggers trafficking of aquaporins-2 water channels from intracellular vesicles to the apical plasma membranes of the collecting duct cells of nephrons. These processes allow water to be reabsorbed, leading to direct water retention. Naturally, antagonism of vasopressin $\mathrm{V}_{2}$ receptors will directly affect this pathway of water reabsorption independent of electrolyte transfer, leading to free water removal or "aquaresis."

The role of vasopressin in patients with heart failure has been studied as far back as 1968, when Yamane (1968) reported that $50 \%$ of patients with advanced heart failure have increased vasopressin levels. These findings were confirmed in the early 1980s with the use of more sensitive radioimmunoassay measurements (Goldsmith et al. 1983). The attempt to develop safe and effective pharmacologic agents to block the effects of AVP has met challenges of poor bioavailability, short half-lives, and partial agonistic properties of various compounds (Schrier \& Martin 1998).

Recently however, several nonpeptide vasopressin receptor antagonists have entered clinical development. Tolvaptan, an oral, once-daily, $\mathrm{V}_{2}$ receptor antagonist synthesized by Otsuka Pharmaceutical Co. Ltd, is the first compound to be developed. Other $V_{2}$ receptor antagonists, lixivaptan (developed by CardioKline, Inc) and satavaptan (developed by Sanofi-Aventis) are undergoing late-stage clinical trials. Conivaptan $\left(\right.$ Vaprisol ${ }^{\circledR}$, developed by Astellas Pharma US, Inc.), an intravenous dual $\mathrm{V}_{1 \mathrm{~A}} \mathrm{~N}_{2}$ receptor antagonist is the only vasopressin receptor antagonist currently approved by the FDA for use in the US. The debate regarding the pros and cons of $V_{2}$ only blockade versus dual $V_{1 A} N_{2}$ antagonism has been outlined in a recent review article (Goldsmith 2006). Table 4 summarizes the clinical studies conducted on tolvaptan in patients with heart failure.

\section{Decrease in fluid balance and bodyweight}

Measurement of daily weight is used as an indicator of total body volume and effectiveness of diuresis in patients hospitalized with AHFS. Therefore, changes in bodyweight have been of primary interest in assessing the effectiveness of tolvaptan in treating congestion. In an evaluation investigating the effects of singledose tolvaptan administration in healthy individuals, increases were seen in mean serum sodium concentrations $(4-6 \mathrm{mEq} / \mathrm{L})$, plasma osmolality $(\sim 8 \mathrm{mOsm} / \mathrm{kg})$, and free water clearance ( $\sim 6 \mathrm{~mL} / \mathrm{min}$ ) throughout 0-24 hours, all independent of increasing dosage (Shoaf et al. 2007). Only total urine volume excretion (0-72 hours postdose) increased linearly with dose. Also, increase in plasma tolvaptan concentrations caused urine excretion rate to remain above baseline for a longer period of time (Shoaf et al. 2007).

Reduction in bodyweight was the primary endpoint measure in one of the first studies evaluating the effects of chronic administration of a vasopressin $V_{2}$ receptor blocker in patients with heart failure. This study was a multicenter, double blind, placebocontrolled trial that involved 254 patients with worsening heart failure, irrespective of LVEF (Gheorghiade et al. 2003). Patients were randomly assigned to receive tolvaptan 30,45 , or $60 \mathrm{mg}$ or placebo for 25 days in an outpatient setting in addition to standard congestive heart failure therapy. The primary endpoint was bodyweight change over time, and secondary objectives included changes in peripheral edema, urinary sodium excretion, urine volume, and osmolality. All three doses of tolvaptan resulted in a statistically significant decrease in bodyweight at 24 hours compared with placebo; of interest, the effect did not appear to be dose dependent. This initial weight loss was maintained throughout the study without further reduction in weight beyond the first day. Urine output was also significantly greater in the tolvaptan groups compared with placebo when collected during the first day $(3909,4232,4597$, and $2328 \mathrm{~mL}$ for tolvaptan 30,45 , $60 \mathrm{mg}$, and placebo, respectively) (Gheorghiade et al. 2003).

The favorable effects of oral tolvaptan on fluid balance and bodyweight were confirmed in the ACTIV in CHF trial, in which 319 patients with LVEF $\leq 40 \%$ hospitalized for AHFS were randomized to receive tolvaptan 30,60 , or $90 \mathrm{mg}$ or placebo in addition to standard therapy (Gheorghiade et al. 2004). The major difference from prior studies was the need for hospitalization. The course of therapy included an inpatient period of 10 days, followed by a 7-week outpatient period. The inpatient endpoint was change in bodyweight 24 hours after administration of the drug. Bodyweight decreased significantly in the first day of treatment with tolvaptan (median reduction of 1.90, 2.10 , and $2.05 \mathrm{~kg}$ for tolvaptan 30,60 , and $90 \mathrm{mg}$, respectively) compared with placebo $(0.6 \mathrm{~kg})$. Bodyweight decreased further in all groups during hospitalization. Changes in urine output, a secondary endpoint of the trial, were significantly higher for all tolvaptan groups when compared with the placebo group, and this effect was also maintained throughout the period of hospitalization.

The Efficacy of Vasopressin Antagonism in Heart Failure Outcome Study with Tolvaptan (EVEREST) clinical development program was a series of prospective, multicenter, international, 


\section{Table 4 | Clinical studies on tolvaptan in acute heart failure syndrome (AHFS)}

\begin{tabular}{|c|c|c|c|}
\hline Study aim & $\begin{array}{l}\text { Study design, patients, } \\
\text { and treatment }\end{array}$ & Results & References \\
\hline $\begin{array}{l}\text { Primary endpoint: bodyweight over time } \\
\text { Secondary endpoints: peripheral edema, } \\
\text { urinary sodium excretion, urine volume, urine } \\
\text { osmolality }\end{array}$ & $\begin{array}{l}\text { DB RCT, } n=254 \text { with NYHA class II-III } \\
\text { HF irrespective of EF; } \\
\text { Tol } 30,45 \text {, or } 60 \mathrm{mg} \text {, or placebo for } \\
25 \mathrm{~d}\end{array}$ & $\begin{array}{l}\text { Statistically significant reduction in } \\
\text { bodyweight at } 24 \mathrm{~h} \text { with Tol vs placebo } \\
\text { Established safety and potential } \\
\text { beneficial aquaretic effect of Tol in HF }\end{array}$ & Gheorghiade et al. 2003 \\
\hline $\begin{array}{l}\text { Acute- and intermediate-term effects of Tol } \\
\text { Inpatient endpoint: bodyweight changes } \\
24 \text { h after administration } \\
\text { Outpatient endpoint: worsening HF }\end{array}$ & $\begin{array}{l}\text { DB RCT, } n=319 \text { hospitalized for } \\
\text { worsening heart failure with EF } \leq 40 \% \\
\text { and NYHA class III-IV HF }\end{array}$ & $\begin{array}{l}\text { Bodyweight decreased significantly } 24 \mathrm{~h} \\
\text { after Tol vs placebo } \\
\text { No significant difference in worsening HF } \\
\text { between groups }\end{array}$ & $\begin{array}{l}\text { Gheorghiade et al. } 2004 \\
\text { (ACTIV in CHF) }\end{array}$ \\
\hline $\begin{array}{l}\text { Effects of Tol in the absence of a diuretic on } \\
\text { bodyweight, congestion, and serum sodium } \\
\text { in HF }\end{array}$ & $\begin{array}{l}\text { RCT, } \mathrm{n}=83 \text { with NYHA class II-III HF; } \\
\text { Tol } 30 \mathrm{mg} / \mathrm{d} \text {, Fur } 80 \mathrm{mg} / \mathrm{d} \text {, } \\
\text { Tol } 30 \mathrm{mg} / \mathrm{d}+\text { Fur } 80 \mathrm{mg} / \mathrm{d} \text {, } \\
\text { or placebo }\end{array}$ & $\begin{array}{l}\text { Tol monotherapy and Tol + Fur resulted } \\
\text { in significant reduction in bodyweight at } \\
1 \text { wk vs Fur monotherapy and placebo } \\
\text { Reduction in leg edema, dyspnea, JVP, } \\
\text { rales, and hepatomegaly observed in the } \\
\text { Tol grop vs placebo }\end{array}$ & Udelson et al. 2002 \\
\hline Effect of Tol vs Fur on renal function & $\begin{array}{l}\mathrm{RCT}, \mathrm{n}=14 \text { with NYHA class II-III HF } \\
\text { and } \mathrm{EF} \leq 40 \%\end{array}$ & $\begin{array}{l}\text { Tol and Fur induced similar diuretic } \\
\text { response; RBF increased with Tol, } \\
\text { decreased with Fur; GFR was similar in } \\
\text { the two groups }\end{array}$ & Costello-Boerrigter et al. 2006 \\
\hline $\begin{array}{l}\text { Pharmacodynamics, pharmacokinetics, } \\
\text { clinical safety of Tol } 30 \mathrm{mg} \text { qd vs } 15 \mathrm{mg} \text { bid }\end{array}$ & $\begin{array}{l}\text { DB RCT, } n=40 ; \text { Tol } 30 \mathrm{mg} \text { qd or } \\
15 \mathrm{mg} \text { bid for } 7 \mathrm{~d}\end{array}$ & Tol $30 \mathrm{mg}$ qd =15 mg bid & Hauptman et al. 2005 \\
\hline $\begin{array}{l}\text { Primary endpoint: composite of change in } \\
\text { global clinical status and bodyweight at } \\
7 \text { days or the day of discharge (short-term } \\
\text { trials); all-cause mortality and cardiovascular } \\
\text { death or hospitalization for heart failure (long } \\
\text { term trials) }\end{array}$ & $\begin{array}{l}\text { DB RCTs (two short term, one long } \\
\text { term), } n=4133 ; \text { Tol } 30 \mathrm{mg} / \mathrm{d} \\
\text { or placebo }\end{array}$ & $\begin{array}{l}\text { Significant weight reduction with Tol } \\
\text { compared with placebo, significant } \\
\text { improvement in dyspnea on day } 1 \text { of } \\
\text { hospitalization compared with placebo }\end{array}$ & $\begin{array}{l}\text { Gheorghiade et al. 2003; } \\
\text { Konstam et al. } 2007 \text { (EVEREST) }\end{array}$ \\
\hline $\begin{array}{l}\text { Evaluate the effect of long term Tol on } \\
\text { LVEDV and LV function }\end{array}$ & $\begin{array}{l}\mathrm{RCT}, \mathrm{n}=240 \text { with } \mathrm{HF} \text {; Tol } 30 \mathrm{mg} / \mathrm{d} \\
\text { or placebo for } 1 \text { year; radionuclide } \\
\text { ventriculography was performed at } \\
\text { baseline, week } 54 \text {, and } 1 \text { week after } \\
\text { completion of therapy at week } 55\end{array}$ & $\begin{array}{l}\text { No significant difference between } \\
\text { changes in LVEDV index between the } \\
\text { two groups }\end{array}$ & Udelson et al. 2007a (METEOR) \\
\hline $\begin{array}{l}\text { Hemodynamic effect of Tol in patients with } \\
\text { advanced heart failure due to } \\
\text { systolic dysfunction }\end{array}$ & $\begin{array}{l}\text { RCT, } n=180 \text { with stable NYHA class } \\
\text { III or IV HF and LVEF } \leq 40 \% \text {; single } \\
\text { dose Tol } 15,30,60 \mathrm{mg} \text {, or placebo } \\
\text { during hemodynamic monitoring }\end{array}$ & $\begin{array}{l}\text { All three doses of tolvaptan significantly } \\
\text { affected the peak change in PCWP after } \\
3-8 \mathrm{~h} \text { compared with placebo }\end{array}$ & Udelson et al. 2007b (ECLIPSE) \\
\hline
\end{tabular}

randomized, double-blind, placebo-controlled trials: two identical short-term trials (trials $\mathrm{A}$ and $\mathrm{B}$ ) and one long-term outcome study. The primary endpoint of the short-term trials was a composite of change in global clinical status and bodyweight at 7 days or the day of discharge, whichever was earlier (Konstam et al. 2007). EVEREST included patients with LVEF $\leq 40 \%$ and known chronic heart failure admitted for AHFS who were randomized within 48 hours of hospitalization to receive fixed-dose oral tolvaptan (30 mg/day) or matching placebo. A total of 2048 patients were randomized in trial A (1018 patients in the tolvaptan group and 1030 in the placebo group), and 2085 patients in trial B (1054 in the tolvaptan group and 1031 in the placebo group). Mean bodyweight at day 1 was reduced by $1.76 \mathrm{~kg}$ in the tolvaptan group and by $0.97 \mathrm{~kg}$ in the placebo group $(P<0.001)$. This effect was maintained long after the index hospitalization. In the short-term studies, tolvaptan resulted in a statistically significant improvement relative to placebo on the primary endpoint, the composite of patient-assessed global clinical status and bodyweight change at day $7(P=0.0004)$ or discharge $(P<0.0001)$. While the improvements in both scales were numerically in favor of tolvaptan, the change in average bodyweight at day 7 or discharge was significantly greater with tolvaptan than with placebo in both short-term trials. Mean weight reductions of $3.35 \mathrm{~kg}$ versus $2.73 \mathrm{~kg}(P<0.001)$ and $3.77 \mathrm{~kg}$ versus $2.79 \mathrm{~kg}(P<0.001)$ were seen at day 7 in each trial with tolvaptan and placebo, respectively (Gheorghiade et al. 2007). Overall, there was a consistent favorable effect on negative fluid balance and reduction in bodyweight as a result of the aquaretic effects of tolvaptan, and the evidence in this regard is clear.

\section{Decrease in symptom burden}

In the ACTIV in CHF trial, symptoms of heart failure improved in all patients during hospitalization; however, the differences were not significant except for dyspnea $(P=0.04)$ (Gheorghiade 
Tolvaptan | place in therapy review

et al. 2004). The effects of tolvaptan on symptom burden of AHFS were further evaluated in EVEREST. In both short-term trials more patients reported day 1 improvements in dyspnea with tolvaptan than with placebo: $76.7 \%$ versus $70.6 \%$ in the first trial and $72.1 \%$ versus $65.3 \%$ in the other (both $P<0.001$ ). Day 1 patient-assessed dyspnea, bodyweight, day 7 edema, and all secondary endpoints of this study improved significantly in the tolvaptan-treated group. However, the improvement in edema from baseline at day 7 in the tolvaptan-treated group reached statistical significance in only one of the two shortterm studies (Gheorghiade et al. 2007). Post-hoc analysis showed significant improvement in dyspnea and rales over the first 4 inpatient days, and in orthopnea and jugular venous distension in the first 3 inpatient days in patients treated with tolvaptan compared with placebo. Taken together, the evidence that tolvaptan provided incremental relief of symptom burden in hospitalized patients is relatively clear.

\section{Safety and tolerability}

At this stage, there is adequate evidence that tolvaptan is a relatively safe and well-tolerated drug for the treatment of heart failure. The most common side effects experienced with tolvaptan have been generally mild and associated with the pharmacologic effect of the drug on the regular feedback mechanism as a result of free water wasting; most commonly dry mouth, thirst, and polyuria (Gheorghiade et al. 2003, 2004; Konstam et al. 2007; Udelson et al. 2007a). In the ACTIV in CHF study, the most common side effect of tolvaptan was thirst, which was experienced by $\sim 10 \%$ of patients (Gheorghiade et al. 2004). Even though $85 \%$ of patients in ACTIV in CHF reported adverse events, there were no significant differences in adverse events in patients receiving tolvaptan or placebo.

In EVEREST, use of tolvaptan was not associated with increased incidence of hypotension, tachycardia, renal failure, hypokalemia, hypomagnesemia, or liver function abnormalities (Konstam et al. 2007). As expected, tolvaptan increased thirst and dry mouth $(P<0.001)$. Hypernatremia occurred in $1.7 \%$ of tolvaptan recipients, compared with $0.5 \%$ of those taking placebo. Adverse events resulting in study drug discontinuation occurred in $6.5 \%$ and $5.5 \%$ of the tolvaptan and placebo groups, respectively. The only adverse event resulting in study drug discontinuation that was significantly different between the two groups was thirst ( $n=7$ versus $n=0 ; P=0.02$ ), even though these rates were very low for a large clinical trial (Konstam et al. 2007). Dry mouth resulted in drug discontinuation in four tolvaptan and none of the placebo patients.

\section{Improvement in quality of life}

Earlier studies revealed no significant differences in the selfreported quality of life assessment between the tolvaptan and placebo groups. In EVEREST, a prespecified health-related quality of life assessment using the Kansas City Clinical Questionnaire was conducted, and showed no significant differences between the treatment groups at outpatient visit week 1. However, during the last scheduled assessment at study end, three out of the 10 study domains (quality of life, social limitation, and overall summary score) showed statistically significant changes favoring tolvaptan; the remaining domains also favored tolvaptan numerically but did not reach statistical significance (Konstam et al. 2007). These mixed results provide only some reassurance of the effect of tolvaptan in improving health status, which has to balance the aforementioned troublesome side effects of thirst and dry mouth.

\section{Neutral effects in morbidity and mortality}

Admission for heart failure is associated with significant risk for patients, with an average inhospital mortality rate of $4 \%$ (Adams et al. 2005). Despite the emergence of new agents for the treatment of heart failure in the past few years, none have resulted in a substantial decrease in heart failure hospitalizations or mortality in this setting. The potential effects of tolvaptan on long-term morbidity and mortality have been generated from the concept of beneficial blockade of over-activated neurohormonal systems. Indeed, the ACTIV in CHF trial had two primary endpoints to assess both the acute- and intermediate-term effects of tolvaptan. The outpatient endpoint was worsening heart failure (defined as rehospitalization, unscheduled visit for heart failure, or death at 60 days). The results did not show a significant difference in worsening heart failure between patients treated with tolvaptan compared with placebo, although in post-hoc analysis event-free survival at 60 days was longer for the tolvaptan group, and total mortality was lower particularly in patients with elevated blood urea (BUN) nitrogen and with severe systemic congestion (Gheorghiade et al. 2004). These findings were also confirmed in the one-year remodeling study, Multicenter Evaluation of Tolvaptan Effect on Remodeling (METEOR). In METEOR, only six deaths (5\%) occurred in the tolvaptan group compared with 11 in the placebo group $(9.2 \%)$, but worsening heart failure (defined as hospitalization or emergency department visit for heart failure or unscheduled treatment with intravenous diuretics) was approximately $28 \%$ in the tolvaptan group compared with $18 \%$ in the placebo group. An endpoint not previously specified, time to death or worsening heart failure, was significantly reduced in the tolvaptan group $(P=0.03)$ (Udelson et al. 2007a).

In the long-term arm of EVEREST, 4133 patients were randomized to receive tolvaptan or placebo for a minimum of 60 days, in addition to standard therapy. Tolvaptan did not affect the two primary endpoints of all-cause mortality and cardiovascular death or hospitalization for heart failure, with a median follow-up of 9.9 months (Konstam et al. 2007) (Table 5). In the tolvaptan arm 871 patients reached the composite endpoint of cardiovascular death or hospitalization for heart failure versus 829 patients in the placebo arm (42.0\% versus $40.2 \% ; P=0.55)$. Inhospital mortality was not different in the tolvaptan and placebo groups $(2.4 \%$ and $2.9 \%$, respectively), and the corresponding all-cause mortality rates were $25.9 \%$ and $26.3 \%$ (Table 5 ).

With the paucity of new agents targeting AHFS (most of them challenged with questionable long-term safety profiles), the 


\begin{tabular}{|c|c|c|c|c|c|}
\hline & \multicolumn{2}{|c|}{ Number of patients $(\%)$} & \multirow[b]{2}{*}{$\begin{array}{l}\text { Hazard ratio } \\
\text { ( } 95 \% \\
\text { confidence } \\
\text { interval) }\end{array}$} & \multicolumn{2}{|c|}{$P$ value } \\
\hline & $\begin{array}{l}\text { Tolvaptan } \\
\text { ( } \mathrm{n}=2072)\end{array}$ & $\begin{array}{l}\text { Placebo } \\
(\mathrm{n}=2061)\end{array}$ & & Superiority & Noninferiority \\
\hline \multicolumn{6}{|l|}{ Primary endpoints } \\
\hline all-cause mortality & $537(25.9)$ & $543(26.3)$ & $0.98(0.87-1.11)$ & $0.68^{\mathrm{a}}$ & $<0.001$ \\
\hline $\begin{array}{l}\text { cardiovascular death or } \\
\text { hospitalization for heart failure }\end{array}$ & $871(42.0)$ & $829(40.2)$ & $1.04(0.95-1.14)$ & $0.55^{\mathrm{a}}$ & \\
\hline \multicolumn{6}{|l|}{ Secondary endpoints } \\
\hline $\begin{array}{l}\text { cardiovascular death or } \\
\text { hospitalization }\end{array}$ & $1006(48.5)$ & $958(46.4)$ & $1.04(0.95-1.14)$ & $0.52^{\mathrm{a}}$ & \\
\hline $\begin{array}{l}\text { incidence of cardiovascular } \\
\text { mortality }\end{array}$ & $421(20.3)$ & $408(19.8)$ & & $0.67^{\mathrm{b}}$ & \\
\hline $\begin{array}{l}\text { incidence of clinical worsening } \\
\text { of heart failure (death, hospitalization, } \\
\text { or unscheduled visits) }\end{array}$ & $757(36.5)$ & $739(35.8)$ & & $0.62^{\mathrm{b}}$ & \\
\hline
\end{tabular}

availability of evidence showing the lack of harm with add-on tolvaptan represents valuable and reassuring information for its use in this patient population. However, the neutral effects on morbidity and mortality were a slight disappointment following the favorable phase II data from ACTIV in CHF, where post-hoc evaluation suggested that 60-day therapy should lower mortality rates in tolvaptan-treated patients with renal dysfunction or severe systemic congestion.

\section{Improvement in serum sodium}

Hyponatremia is a marker of poor outcome in heart failure (Kearney et al. 2002). Vasopressin receptor antagonists induce free water excretion by blocking the "antidiuretic" effect of AVP on the kidney collecting tubules, resulting in an increase in plasma sodium.

In the ACTIV in CHF trial, patients treated with tolvaptan had an increase in serum sodium after 24 hours of treatment, while serum sodium decreased in the placebo-treated group. Also patients with serum sodium $<136 \mathrm{mEq} / \mathrm{L}$ had a rapid increase and often normalization in concentration that was maintained throughout the study (Gheorghiade et al. 2004). Post-hoc analysis of ACTIV in CHF revealed that the 60-day mortality among patients with improved serum sodium (increase of $>2 \mathrm{mEq} / \mathrm{L}$ by the time of discharge) was $11.1 \%$, compared with $21.7 \%$ in those patients whose serum sodium did not improve or improved by $<2 \mathrm{mEq} / \mathrm{L}$. After adjustment for covariates, improvement in serum sodium at discharge was a significant predictor of mortality at 60 days postdischarge. In EVEREST, the effects of tolvaptan on sodium were consistent with prior studies. Among patients with baseline serum sodium levels $<134 \mathrm{mEq} / \mathrm{L}$, mean serum sodium concentrations increased by $5.49 \pm 5.77 \mathrm{mEq} / \mathrm{L}$ at day 7 or discharge with tolvaptan, compared with $1.85 \pm 5.10 \mathrm{mEq} / \mathrm{L}$ in the placebo group $(P<0.001)$. This effect was observed as early as day 1 and was maintained through 40 weeks of treatment (Konstam et al. 2007).

These findings are consistent with those of the recently published Study of Ascending Levels of Tolvaptan in Hyponatremia (SALT) trials, with corresponding improvements in mental component summary of the Short Form-12 Health Survey in hyponatremic patients receiving tolvaptan compared with placebo (Schrier et al. 2006). There was a lack of mortality or morbidity benefit favoring tolvaptan in EVEREST when analyzing the subgroup of patients with a serum sodium $\leq 137 \mathrm{mEq} / \mathrm{L}$, thereby questioning the clinical significance of the previous studies' findings. The EVEREST investigators pointed out that only $8 \%$ of the population has baseline serum sodium levels $<134 \mathrm{mEq} / \mathrm{L}$ (the prespecified exclusion criterion).

\section{Effect on renal function}

Worsening renal function is not uncommon in acute decompensated heart failure, occurring in approximately $30 \%$ of patients (Cowie et al. 2006). Worsening renal function has been reported to be associated with increased all-cause mortality in patients with heart failure (Dries et al. 2000; Hillege et al. 2000). In fact, two out of three variables that are the strongest predictors of mortality in hospitalized AHFS patients involve renal function (Fonarow et al. 2005). In particular, higher doses of diuretics (often via the intravenous route) are administered during treatment of AHFS, which may place the patient at risk of worsening renal function (Butler et al. 2004).

The renal effects of tolvaptan compared with furosemide have been studied in a small mechanistic, open-label, randomized placebo-controlled crossover study in 14 patients with heart 
Tolvaptan | place in therapy review

failure. As expected, tolvaptan administration was associated with equivalent diuresis without an increase in sodium and potassium excretion (Costello-Boerrigter et al. 2006). Tolvaptan also increased renal blood flow, whereas furosemide administration resulted in decreased renal blood flow compared with placebo. Hence, free water excretion and preservation of renal blood flow make $V_{2}$ receptor blockers attractive for the treatment of patients with AHFS.

It is important to emphasize that the use of tolvaptan has been tested in clinical trials as an addition to loop diuretics instead of use in lieu of diuretics. The ACTIV in CHF and EVEREST trials further demonstrated tolvaptan's ability to reduce congestion without causing incremental renal impairment. In EVEREST, there was a significant difference favoring tolvaptan in BUN levels between the two groups at day 1, an effect that tended to persist long after discharge. At day 7 or discharge, mean BUN levels had increased by $1.94 \pm 11.7 \mathrm{mg} / \mathrm{dL}$ in the tolvaptan group and by $3.30 \pm$ $12.16 \mathrm{mg} / \mathrm{dL}$ in the placebo group $(P<0.001)$, with corresponding increases in mean serum creatinine levels of $0.08 \pm 0.31 \mathrm{mg} / \mathrm{dL}$ and $0.03 \pm 0.35 \mathrm{mg} / \mathrm{dL}(P<0.001)$ (Gheorghiade et al. 2007). In posthoc analysis of the EVEREST trial, mean reduction in furosemide dosage during hospitalization was significantly greater in the tolvaptan than the placebo group ( -55.8 versus $-42.9 \mathrm{mg} / \mathrm{day}$; $P=0.002$ ) (Gheorghiade et al. 2007). This reduction in diuretic use may also be one mechanism by which a lowering of BUN was observed in the tolvaptan group, and less usage of furosemide may potentially decrease the commonly observed side effects associated with diuretic use, including worsening renal failure and electrolyte abnormalities.

\section{Neutral effect on cardiac remodeling}

Cardiac remodeling is now recognized as a key aspect in disease progression and has been viewed as a reliable surrogate for heart failure. The effects of tolvaptan on cardiac remodeling have been examined in the METEOR trial. This multicenter, randomized, double-blind, placebo-controlled study involved 240 patients with mild-to-moderate [New York Heart Association (NYHA) II-III] chronic heart failure with LVEF $\leq 30 \%$, and compared oral tolvaptan $30 \mathrm{mg}$ daily with placebo. The primary endpoint was left ventricular end diastolic volume (LVEDV) calculated by radionuclide ventriculography at baseline, week 54 , and 1 week after completion of therapy at week 55 . The results showed no significant difference in changes in LVEDV index between the two groups during 1 year of follow up (Udelson et al. 2007a). Also, there were no statistically significant differences in LVEF between tolvaptan and control groups $(+1.32 \%$ versus $+0.52 \%$; $P=0.16)$.

\section{Improvement in hemodynamic measures}

Concerns regarding the blockade of $V_{2}$ receptors generating overstimulation of $\mathrm{V}_{1 \mathrm{~A}}$ receptor effects on vasoconstriction have prompted extensive investigations on the hemodynamic effects of tolvaptan. It is reassuring that across all clinical studies, there has been no significant difference in changes of blood pressure or heart rate between the tolvaptan and placebo groups. It is important to emphasize that patients with systolic blood pressure $<90 \mathrm{mmHg}$ were excluded in EVEREST and the systolic blood pressure cut off was even higher in the ACTIV in CHF trial (110 mmHg).

The acute hemodynamic effects of tolvaptan in AHFS were carefully evaluated in the Effect of Tolvaptan on Hemodynamic Parameters in Subjects with Heart Failure (ECLIPSE) trial, in which 180 patients with stable advanced heart failure (NYHA IIIIV, LVEF $\leq 40 \%$ ) and pulmonary capillary wedge pressure (PCWP) $\geq 18 \mathrm{mmHg}$ were randomized to receive a single dose of tolvaptan 15,30 , or $60 \mathrm{mg}$ or placebo during continuous central hemodynamic monitoring (Udelson et al. 2007b). Measurements were obtained for 12 hours after administration of the drug while patients were continued on standard heart failure medications that included beta blockers, diuretics, ACE inhibitors and/or angiotensin receptor blockers. At a mean PCWP of $25 \mathrm{mmHg}$, all three doses of tolvaptan significantly affected the peak change in PCWP 3-8 hours after administration $(-6.38 \pm 0.62 \mathrm{mmHg}$ with tolvaptan $15 \mathrm{mg}$, $-5.67 \pm 0.70 \mathrm{mmHg}$ with $30 \mathrm{mg}$, and $-5.71 \pm 0.65 \mathrm{mmHg}$ with $60 \mathrm{mg} ; P<0.05)$ compared with placebo $(-4.16 \pm 0.67 \mathrm{mmHg})$, all with corresponding increases in urine volume at 3 hours after administration $(P<0.0001)$. None of the other secondary outcome measures, including cardiac output, systemic vascular resistance, heart rate, or blood pressure, showed significant changes between the tolvaptan and placebo groups (Udelson et al. 2007b).

\section{Economic evidence and resource utilization}

There have been no formal economic evaluations or assessments of health benefits and value in terms of quality-adjusted lifeyears regarding the use of tolvaptan in AHFS. Based on the outcome analysis, there was no incremental benefit from reduced cardiovascular mortality or heart failure hospitalizations. Therefore, further justification is necessary to identify patient subgroups that may offset the incremental cost of short-term symptomatic improvement.

\section{Patient group/population}

The current evidence for tolvaptan in AHFS is primarily restricted to the use of fixed-dose administration rather than alternative dosing approaches, such as dose adjustment based on clinical response. Therefore, this may not preclude the subgroup of volume-overloaded patients who are refractory to initial loop diuretic approach or those with significant electrolyte or cardiorenal compromise. While tolvaptan likely provides beneficial reversal of hyponatremia, the clinical consequence of this resolution has yet to translate into clinical benefits, largely because of the relatively small patient population experiencing hyponatremia (only $8 \%$ in EVEREST).

Furthermore, morbidity and mortality effects of tolvaptan have only been evaluated in patients hospitalized with signs and symptoms of congestion and reduced LVEF. While earlier studies on tolvaptan have included those with preserved LVEF (Table 6), these patients were excluded from larger studies. 


\begin{tabular}{|c|c|c|c|c|}
\hline & \multicolumn{3}{|c|}{ Tolvaptan } & \multirow{2}{*}{$\begin{array}{c}\text { Placebc } \\
(n=63)\end{array}$} \\
\hline & $\begin{array}{l}30 \mathrm{mg} \\
(\mathrm{n}=64)\end{array}$ & $\begin{array}{l}45 \mathrm{mg} \\
(\mathrm{n}=64)\end{array}$ & $\begin{array}{l}60 \mathrm{mg} \\
(\mathrm{n}=63)\end{array}$ & \\
\hline \multicolumn{5}{|c|}{ Ejection fraction } \\
\hline$<40$ & 26 (40.6) & $21(23.4)$ & $24(38.1)$ & 19 (30.2) \\
\hline$\geq 40$ & $14(21.9)$ & $14(21.9)$ & $9(14.3)$ & $8(12.7)$ \\
\hline unknown & $24(37.5)$ & $29(45.3)$ & $28(44.4)$ & $32(50.8)$ \\
\hline
\end{tabular}

There remains a lack of clinical trial data examining the role of tolvaptan, or indeed any other drug, in patients with preserved systolic function presenting with AHFS. Based on our current understanding of the clinical presentation in patients with impaired versus preserved LVEF with AHFS, it is speculated that the effects of tolvaptan may not differ considerably between the two groups but further studies are warranted to confirm these speculations.

\section{Dosage, administration, and formulations}

In February 2008 the European Medicines Agency (EMEA) accepted a Marketing Authorization Application for tolvaptan to be used in the setting of worsening heart failure and hyponatremia. In June 2008, the FDA advisory panel recommended the approval of tolvaptan for hypervolemic or euvolemic hyponatremia. Tolvaptan can be given orally once daily and has been studied in doses ranging from $15 \mathrm{mg}$ to $90 \mathrm{mg}$ daily. Results from clinical trials on tolvaptan have not shown a dose-dependent response and the frequency of adverse effects associated with tolvaptan was not increased with larger doses (Gheorghiade et al. 2003, 2004).

In EVEREST, tolvaptan was used as a $30 \mathrm{mg}$ daily oral dose. There was no difference in the pharmacokinetics or pharmacodynamics of tolvaptan given as $30 \mathrm{mg}$ once daily or $15 \mathrm{mg}$ twice daily when these two doses were compared in a study of 40 heart failure patients in a double-blind fashion (Hauptman et al. 2005).

Conivaptan is a dual $V_{1} N_{2}$ vasopressin receptor antagonist approved for usage in the US. While conivaptan is metabolized by cytochrome P450 3A4 (CYP3A4), the drug is also a potent inhibitor of CYP3A4. Hence, conivaptan tends to increase plasma concentrations of coadministered drugs that are primarily metabolized by CYP3A4. When studied in oral form, conivaptan demonstrated multiple drug interactions, limiting its FDA approval to intravenous usage only.

As tolvaptan is also primarily metabolized by the CYP3A4 pathway, coadministration of calcium channel blockers, macrolide antibiotics, or azole antifungals may require dose adjustments. Coadministration of tolvaptan has been shown to increase the maximal plasma concentration of ketoconazole by $248 \%$. However, there appear to be no drug interactions between tolvaptan and amiodarone or warfarin (Wang et al. 2003; Shoaf et al. 2005). Additional studies are needed to better assess the level of potential drug interactions associated with tolvaptan.

\section{Place in therapy}

Consistent with the neurohormonal hypothesis, persistent neurohormonal overactivation may drive the disease process to further deterioration in patients with AHFS. As AVP is a true neurohormone, antagonism of AVP at the core of the development of the congestive state has been postulated as a potential therapeutic target. However, the attempt to test this hypothesis with long-term antagonism of vasopressin $\mathrm{V}_{2}$ receptors failed to demonstrate incremental benefit over standard medical therapy including loop diuretics and neurohormonal antagonists in patients with heart failure.

The clinical trial program with tolvaptan has however produced an extensive safety profile, which is still an important assurance for healthcare providers using this agent. The current evidence suggests that tolvaptan is effective and long lasting in relieving congestion by free water removal without adversely affecting kidney function. It is still most likely beneficial in patients with profound volume overload and existing or impending cardiorenal compromise, either in the setting of ineffective diuresis (as in the case of ineffective weight loss and net urine output despite escalating doses of diuretics) or those with significant (or sensitive to) electrolyte abnormalities that would have further detrimental effects with overzealous diuretic therapy. There have been no randomized control trials directed to these specific patient populations to generate evidence that supports the potential benefits in these subgroups. As an aquaretic, tolvaptan is unlikely to replace loop diuretics unless it shows an incremental mortality benefit. If future studies confirm the neutral mortality effect of tolvaptan, its place in therapy will most likely fall within the treatment of congestion as an effective drug to reduce the adverse effects of high dose diuretic use or renal insufficiency in ADHF.

Based on the experience of EVEREST, the use of tolvaptan beyond the time of improvement in fluid balance and clinical status is not justified. Furthermore, side effects of $V_{2}$ receptor antagonists like thirst and mouth dryness will likely complicate long-term adherence to this medication. It is equally important to point out that with the lack of data of an incremental mortality benefit, routine use of $V_{2}$ receptor antagonists will unlikely be justified especially with the likely cost differential compared to loop diuretics, except in aforementioned subgroups that would need careful confirmation of efficacies and economic justification.

Acknowledgements: $\mathrm{Dr}$ Tang has received prior one-time honorarium as a consultant from Otsuka Pharmaceuticals and from Astellas Pharmaceuticals.

\section{References}

Abraham WT, Cheng ML, Smoluk G; Vasodilation in the Management of Acute Congestive Heart Failure (VMAC) Study Group. Clinical and hemodynamic effects of nesiritide (B-type natriuretic peptide) in patients with decompensated heart failure receiving beta blockers. Congest Heart Fail. 2005;11:59-64. 
Tolvaptan | place in therapy review

Adams KF Jr, Fonarow GC, Emerman CL, et al: ADHERE Scientific Advisory Committee and Investigators. Characteristics and outcomes of patients hospitalized for heart failure in the United States: rationale, design, and preliminary observations from the first 100,000 cases in the Acute Decompensated Heart Failure National Registry (ADHERE). Am Heart J. 2005;149:209-216.

Bayliss J, Norell M, Canepa-Anson R, Sutton G, Poole-Wilson P. Untreated heart failure: clinical and neuroendocrine effects of introducing diuretics. $\mathrm{Br}$ Heart J. 1987;57:17-22.

Berry C, Murdoch DR, McMurray JJ. Economics of chronic heart failure. Eur J Heart Fail. 2001;3:283-291.

Butler J, Forman DE, Abraham WT, et al. Relationship between heart failure treatment and development of worsening renal function among hospitalized patients. Am Heart J. 2004;147:331-338.

Cleland JG, Freemantle N, Coletta AP, Clark AL. Clinical trials update from the American Heart Association: REPAIR-AMI, ASTAMI, JELIS, MEGA, REVIVE-II, SURVIVE, and PROACTIVE. Eur J Heart Fail. 2006;8:105-110.

Cleland JG, Coletta AP, Abdellah AT, et al. Clinical trials update from the American Heart Association 2006: OAT, SALT 1 and 2, MAGIC, ABCD, PABACHF, IMPROVE-CHF, and percutaneous mitral annuloplasty. Eur J Heart Fail. 2007;9:92-97

Cohn JN, Franciosa JA, Francis GS, et al. Effect of short-term infusion of sodium nitroprusside on mortality rate in acute myocardial infarction complicated by left ventricular failure: results of a Veterans Administration cooperative study. N Engl J Med. 1982;306:1129-1135.

Costanzo MR, Guglin ME, Saltzberg MT, et al; UNLOAD Trial Investigators. Ultrafiltration versus intravenous diuretics for patients hospitalized for acute decompensated heart failure. J Am Coll Cardiol. 2007;49:675-683.

Costello-Boerrigter LC, Smith WB, Boerrigter G, et al. Vasopressin-2-receptor antagonism augments water excretion without changes in renal hemodynamics or sodium and potassium excretion in human heart failure. Am J Physiol Renal Physiol. 2006;290:F273-F278.

Cotter G, Metzkor E, Kaluski E, et al. Randomised trial of high-dose isosorbide dinitrate plus low-dose furosemide versus high-dose furosemide plus low-dose isosorbide dinitrate in severe pulmonary oedema. Lancet. 1998;351:389-393.

Cuffe MS, Califf RM, Adams KF Jr, et al. Short-term intravenous milrinone for acute exacerbation of chronic heart failure: A randomized controlled trial. JAMA. 2002;287:1541-1547.

Dries DL, Exner DV, Domanski MJ, Greenberg B, Stevenson LW. The prognostic implications of renal insufficiency in asymptomatic and symptomatic patients with left ventricular systolic dysfunction. J Am Coll Cardiol. 2000;35:681-689.

Fonarow GC, Adams KF Jr, Abraham WT, Yancy CW, Boscardin WJ; ADHERE Scientific Advisory Committee, Study Group, and Investigators. Risk stratification for in-hospital mortality in acutely decompensated heart failure: classification and regression tree analysis. JAMA. 2005;293:572-580.

Formiga F, Chivite D, Manito N, Casas S, Llopis F, Pujol R. Hospitalization due to acute heart failure. Role of the precipitating factors. Int $J$ Cardiol. 2007;120:237-241.

Gandhi SK, Powers JC, Nomeir AM, et al. The pathogenesis of acute pulmonary edema associated with hypertension. N Engl J Med. 2001;344: $17-22$

Gheorghiade M, Niazi I, Ouyang J, et al. Vasopressin V2-receptor blockade with tolvaptan in patients with chronic heart failure: results from a double-blind, randomized trial. Circulation. 2003;107:2690-2696.

Gheorghiade M, Gattis WA, O'Connor CM, et al. Effects of tolvaptan, a vasopressin antagonist, in patients hospitalized with worsening heart failure: a randomized controlled trial. JAMA. 2004;291:1963-1971.

Gheorghiade M, Mebazaa A. Introduction to acute heart failure syndromes. Am J Cardiol. 2005;96:1G-4G.

Gheorghiade M, Konstam MA, Burnett JC Jr, et al. Short-term clinical effects of tolvaptan, an oral vasopressin antagonist, in patients hospitalized for heart failure: The EVEREST Clinical Status Trials. JAMA. 2007;297:1332-1343.

Goldsmith SR, Francis GS, Cowley AW Jr, Levine TB, Cohn JN. Increased plasma arginine vasopressin levels in patients with congestive heart failure. J Am Coll Cardiol. 1983;1:1385-1390.
Goldsmith SR. Is there a cardiovascular rationale for the use of combined vasopressin V1a/V2 receptor antagonists? Am J Med. 2006;119(Suppl. 1): S93-S96.

Guiha NH, Cohn JN, Mikulic E, Franciosa JA, Limas CJ. Treatment of refractory heart failure with infusion of nitroprusside. N Engl J Med. 1974;291:587-592.

Hauptman PJ, Zimmer C, Udelson J, et al. Comparison of two doses and dosing regimens of tolvaptan in congestive heart failure. $J$ Cardiovasc Pharmacol. 2005;46:609-614.

Heart Failure Society Of America. Executive summary: HFSA 2006 Comprehensive Heart Failure Practice Guideline. J Card Fail. 2006;12:10-38.

Hillege HL, Girbes AR, de Kam PJ, et al. Renal function, neurohormonal activation, and survival in patients with chronic heart failure. Circulation. 2000;102:203-210.

Kearney M, Fox KA, Lee AJ, et al. Predicting death due to progressive heart failure in patients with mild-to-moderate chronic heart failure. J Am Coll Cardiol. 2002;40:1801-1808.

Komajda M, Follath F, Swedberg K, et al; Study Group on Diagnosis of the Working Group on Heart Failure of the European Society of Cardiology. The EuroHeart failure survey programme-a survey on the quality of care among patients with heart failure in Europe. Part 2: Treatment. Eur Heart $\mathrm{J}$. 2003;24:464-474.

Konstam MA, Gheorghiade M, Burnett JC Jr, et al. Effects of oral tolvaptan in patients hospitalized for worsening heart failure: the EVEREST outcome trial. JAMA. 2007;297:1319-1331.

Lee CR, Watkins ML, Patterson JH, et al. Vasopressin: a new target for the treatment of heart failure. Am Heart J. 2003;146:9-18.

Liang CS, Sherman LG, Doherty JU, Wellington K, Lee VW, Hood WB Jr. Sustained improvement of cardiac function in patients with congestive heart failure after short-term infusion of dobutamine. Circulation. 1984;69:113-119.

Maisel AS. The diagnosis of acute congestive heart failure: Role of BNP measurements. Heart Fail Rev. 2003;8:327-334.

McMurray JJ, Teerlink JR, Cotter G, et al. Effects of tezosentan on symptoms and clinical outcomes in patients with acute heart failure: the VERITAS randomized controlled trials. JAMA. 2007;298:2009-2019.

Mebazaa A, Nieminen MS, Packer M, et al. Levosimendan vs dobutamine for patients with acute decompensated heart failure: The SURVIVE Randomized Trial. JAMA. 2007;297:1883-1891.

Moe GW, Howlett J, Januzzi JL, Zowall H; Canadian Multicenter Improved Management of Patients With Congestive Heart Failure (IMPROVE-CHF) Study Investigators. N-terminal pro-B-type natriuretic peptide testing improves the management of patients with suspected acute heart failure: primary results of the Canadian prospective randomized multicenter IMPROVE-CHF study. Circulation. 2007:115:3103-3110.

Mueller T, Gegenhuber A, Poelz W, Haltmayer M. Biochemical diagnosis of impaired left ventricular ejection fraction-comparison of the diagnostic accuracy of brain natriuretic peptide (BNP) and amino terminal proBNP (NTproBNP). Clin Chem Lab Med. 2004;42:159-163.

Neuberg GW, Miller AB, O'Connor CM, et al. Diuretic resistance predicts mortality in patients with advanced heart failure. Am Heart J. 2002;144:31-38.

Nieminen MS, Böhm M, Cowie MR, et al; ESC Committee for Practice Guidelines (CPG). Executive summary of the guidelines on the diagnosis and treatment of acute heart failure: the Task Force on Acute Heart Failure of the European Society of Cardiology. Eur Heart J. 2005;26:384-416.

Nieminen MS, Brutsaert D, Dickstein K, et al; Heart failure Association, European Society of Cardiology. EuroHeart Failure Survey II (EHFS II): a survey on hospitalized acute heart failure patients: description of population. Eur Heart J. 2006;27:2725-2736.

Opasich C, Rapezzi C, Lucci D, et al; Italian Network on Congestive Heart Failure (IN-CHF) Investigators. Precipitating factors and decision-making processes of short-term worsening heart failure despite "optimal" treatment (from the IN-CHF Registry). Am J Cardiol. 2001;88:382-387.

Packer M. The neurohormonal hypothesis: a theory to explain the mechanism of disease progression in heart failure. J Am Coll Cardiol. 1992;20:248-254. 
Rosamond W, Flegal K, Friday G, et al. Heart disease and stroke statistics2007 update: a report from the American Heart Association statistics Committee and Stroke Statistics Subcommittee. Circulation. 2007;115:e69e171.

Sackner-Bernstein JD, Skopicki HA, Aaronson KD. Risk of worsening renal function with nesiritide in patients with acutely decompensated heart failure. Circulation. 2005;111:1487-1491.

Schiff GD, Fung S, Speroff T, McNutt RA. Decompensated heart failure: symptoms, patterns of onset, and contributing factors. Am J Med. 2003;114:625-630.

Schrier RW, Martin PY. Recent advances in the understanding of water metabolism in heart failure. Adv Exp Med Biol. 1998;449:415-426.

Schrier RW, Gross P, Gheorghiade M, et al. Tolvaptan, a selective oral vasopressin V2-receptor antagonist, for hyponatremia. N Engl J Med. 2006;355:2099-2112.

Shoaf SE, Elizari MV, Wang Z, et al. Tolvaptan administration does not affect steady state amiodarone concentrations in patients with cardiac arrhythmias. J Cardiovasc Pharmacol Ther. 2005;10:165-171.

Shoaf SE, Wang Z, Bricmont P, Mallikaarjun S. Pharmacokinetics, pharmacodynamics, and safety of tolvaptan, a nonpeptide AVP antagonist, during ascending single-dose studies in healthy subjects. J Clin Pharmacol. 2007;47:1498-1507.

Udelson JE, Orlandi C, O’Brien T, Sequeira R, Ouyang J, Konstam MA Vasopressin receptor blockade in patients with congestive heart failure: Results from a placebo controlled, randomized study comparing the effects of tolvaptan, furosemide, and their combination. J Am Coll Cardiol. 2002;39:156A (Abstract).
Udelson JE, McGrew FA, Flores E, et al. Multicenter, randomized, double-blind, placebo-controlled study on the effect of oral tolvaptan on left ventricular dilation and function in patients with heart failure and systolic dysfunction. J Am Coll Cardiol. 2007a;49:2151-2159.

Udelson J. Acute hemodynamic effects of tolvaptan, a vasopressin V-2 receptor blocker, in patients with symptomatic heart failure and systolic dysfunction: The ECLIPSE international, multicenter, randomized placebocontrolled trial. Recent and late breaking trials. Presented at: Heart Failure Society of America Annual Scientific Meeting; September 16-19, 2007b; Washington DC.

Verbalis JG. Vasopressin $\mathrm{V}_{2}$ receptor antagonists. $\mathrm{J} \mathrm{Mol} \mathrm{Endocrinol.}$ 2002;29:1-9.

Wang Z, Shoaf S, Kumara S, et al. Lack of effect of tolvaptan on pharmacokinetics (PK) and pharmacodynamics (PD) of warfarin. Clin Pharmacol Ther. 2003; 73:45-45. Abstract Pll-61.

Yamane Y. Plasma ADH level in patients with chronic congestive heart failure. Jpn Circ J. 1968;32:745-759.

Yu CM, Wang L, Chau E, et al. Intrathoracic impedance monitoring in patients with heart failure: correlation with fluid status and feasibility of early warning preceding hospitalization. Circulation. 2005;112:841-848.

Correspondence: W. H. Wilson Tang, MD, 9500 Euclid Avenue, F25, Cleveland, OH 44195, USA or at tangw@ccf.org 